\title{
Effect of trihalomethane exposure on fetal development
}

\author{
J M Wright, J Schwartz, D W Dockery
}

Occup Environ Med 2003;60:173-180

See end of article for authors' affiliations

......................

Correspondence to: Dr J M Wright, US

Environnmental Protection Agency, National Center for Environmental

Assessment, 26 West

Martin Luther King Jr Drive

(MS-190), Cincinnati,

$\mathrm{OH}$ 45268, USA;

wright.michael@epa.gov

Accepted 10 July 2002
Aims: To examine the effect of trimester specific and pregnancy average total trihalomethane (TTHM) exposure on infant birth weight, low birth weight, and intrauterine growth retardation in term births, as well as gestational age and preterm delivery in all births.

Methods: Cross sectional analysis of 56513 singleton infants born to residents of Massachusetts during 1990. City specific aggregate data were used to estimate maternal exposure to TTHM concentration; individual maternal information was used to adjust for confounding.

Results: Increased pregnancy average and second trimester TTHM exposure were associated with small for gestational age and reductions in birth weight after adjusting for potential confounding variables. Compared to $\leqslant 60 \mu \mathrm{g} / \mathrm{l}$, pregnancy average TTHM exposure over $80 \mu \mathrm{g} / \mathrm{I}$ was associated with a $32 \mathrm{~g}$ reduction in birth weight. There was a $23 \mathrm{~g}$ reduction in birth weight in infants born to mothers exposed to greater than $80 \mu \mathrm{g} / \mathrm{I}$ TTHM during the second trimester. For each $20 \mathrm{\mu g} / \mathrm{l}$ increase in TTHM, the estimated reduction in birth was $2.8 \mathrm{~g}$ for pregnancy average exposure and $2.6 \mathrm{~g}$ for second trimester exposure. An increased risk of small for gestational age births was found for pregnancy average (odds ratio (OR) $1.14 ; 95 \% \mathrm{Cl} 1.02$ to 1.26 ) and second trimester (OR $1.13,95 \% \mathrm{Cl} 1.03$ to 1.24) TTHM levels greater than $80 \mu \mathrm{g} / \mathrm{l}$. There was no evidence of an association between preterm delivery and increased TTHM levels, but there were slight increases in gestational duration associated with TTHM concentrations.

Conclusions: Maternal exposure to THMs may be associated with fetal growth retardation. Our findings are consistent with most previous work, although we generally found smaller effects of TTHMs on low birth weight and intrauterine growth retardation.
D isinfection of drinking water results in the formation of numerous disinfection byproducts (DBPs). The trihalomethanes are typically the most prevalent class of DBPs found in treated water and include chloroform, bromodichloromethane, dibromochloromethane, and bromoform. Chloroform is the most abundant trihalomethane and was the first DBP to be identified as a carcinogen in animals. ${ }^{1}$ Other DBPs reported to be carcinogenic in animal studies include the brominated trihalomethanes, ${ }^{23}$ haloacetic acids, ${ }^{4}$ haloacetonitriles, ${ }^{5} \quad$ bromate, $^{6}$ and 3-chloro-4(dichloromethyl)-5-hydroxy-2(5H)-furanone (MX). ${ }^{7}$ Epidemiological studies provide further evidence, ${ }^{8-15}$ with the most consistent findings for bladder and rectal cancer. ${ }^{16}$ While most research on DBPs has focused on carcinogenic endpoints, reproductive effects have received recent attention. ${ }^{17}{ }^{18}$

Birth defects have been reported in animals exposed to chloroform, ${ }^{19}{ }^{20}$ but chloroform is generally not considered a strong teratogen. ${ }^{21}{ }^{22}$ Chloroform appears to have a subtle effect on fetal development, as growth retardation has been reported in mice exposed to chloroform. ${ }^{19-22}$ Chloroform may directly affect the health of the fetus, since transplacental migration has been shown to occur in humans. ${ }^{23}$ There is little evidence of teratogenicity associated with the brominated THMs. ${ }^{21} 22$

Epidemiological studies provide further evidence that exposure to increased levels of DBPs may be associated with adverse developmental effects. Mothers exposed to water with increased trihalomethane concentrations have been shown to be at greater risk for a variety of pregnancy related complications including birth defects, stillbirths, spontaneous abortions, and fetal growth retardation. ${ }^{17}{ }^{18}$ Total trihalomethane (TTHM) has been the most common measure of DBP exposure in epidemiological studies (table 1). Two studies ${ }^{24} 25$ have shown that mothers with high TTHM exposures were 30\% more likely to have low birth weight $(<2500 \mathrm{~g})$ infants compared to those with low TTHM exposures. Kramer and colleagues $^{28}$ reported a similar effect (odds ratio (OR) 1.3; 95\% confidence interval (CI) 0.8 to 2.2) for chloroform levels greater than $10 \mu \mathrm{g} / \mathrm{l}$ (compared to non-detectable levels). Gallagher and colleagues ${ }^{29}$ reported more than a twofold increase in risk of low birth weight (OR 2.1; 95\% CI 1.0 to 4.8 ) following exposure to TTHMs $>60 \mu \mathrm{g} / \mathrm{l}$ (compared to $\leqslant 20 \mu \mathrm{g} / \mathrm{l}$ ). This effect was more pronounced when restricted to term births (OR 5.9; 95\% CI 2.0 to 17.0). Dodds and colleagues ${ }^{30}$ found little evidence of an association (OR 1.04; $95 \%$ CI 0.92 to 1.18 ) between low birth weight and maternal TTHM exposure $>100$ $\mu \mathrm{g} / \mathrm{l}$ (compared to $<50 \mu \mathrm{g} / \mathrm{l}$ ).

No associations between maternal TTHM exposure and very low birth weight $(<1500 \mathrm{~g})^{27}$ or preterm delivery $\mathrm{y}^{24}$ 28-30 $^{28}$ have been reported. The effect of DBPs on the frequency of small for gestational age (SGA) births has been examined less frequently. Bove ${ }^{27}$ reported a 50\% (OR 1.50; 95\% CI 1.14 to 1.94) excess risk of SGA among mothers in the highest TTHM exposure group $(>100 \mu \mathrm{g} / \mathrm{l}$ compared to $\leqslant 20 \mu \mathrm{g} / \mathrm{l})$ during pregnancy. Dodds and colleagues ${ }^{30}$ did not detect as strong an association (OR 1.08; 95\% CI 0.99 to 1.18 ) between SGA and increased third trimester TTHM exposure, while Kramer and colleague ${ }^{28}$ reported an independent effect of chloroform (OR $1.8 ; 95 \%$ CI 1.1 to 2.9) and bromodicholoromethane (OR 1.7; 95\% CI 0.9 to 2.9 ).

The effect of water source and treatment on adverse developmental outcomes has been evaluated in Massachusetts. Tuthill and colleagues ${ }^{31}$ found no effect of disinfection practice (chlorine dioxide versus chlorine) on birth defects, mean birth

Abbreviations: $\mathrm{BDCM}$, bromodichloromethane; $\mathrm{CHCl}_{3}$, chloroform; $\mathrm{Cl}$, confidence interval; DBP, disinfection byproducts; EPA, Environmental Protection Agency; IUGR, intrauterine growth retardation; LBW, low birth weight; $M X$, 3-chloro-4-(dichloromethyl)-5-hydroxy-2 (5H)-furanone; ND, non-detectable; OR, odds ratio; SGA, small for gestational age; TTHM, total trihalomethane 


\section{Main messages}

- Maternal exposure to disinfection byproducts (total trihalomethanes) in tap water was associated with decreased birth weight and an increased risk of low birth weight and intrauterine growth retardation.

- The small effect estimates reinforce the importance of minimising bias due to confounding and exposure misclassification.

- The large sample size and detailed birth data allowed control for presumed confounding by gestational age, maternal demographics, smoking, prenatal care, and maternal reproductive and medical history.

weight, or prematurity ( $<37$ gestational weeks), but did report an association between chlorine dioxide use and prematurity determined by physician assessment. Aschengrau and colleagues investigated the role of type of water supply ${ }^{32}$ and type of disinfection ${ }^{33}$ on spontaneous abortions, stillbirths, congenital anomalies, and neonatal deaths in Massachusetts. They reported an excess risk of spontaneous abortions in mothers using surface water (OR 2.2; 95\% CI 1.3 to 2.6) compared to ground water users. They also found a higher frequency of stillbirths among mothers using chlorinated surface water (OR 2.6; 95\% CI 0.9 to 7.5 ) compared to those using chloraminated surface water. The authors could not evaluate the role of specific trihalomethane concentrations, since the study periods preceded routine DBP monitoring. In the present study, we evaluated the effect of maternal TTHM exposure on several indices of fetal development. Using data recorded in the Massachusetts birth registry, we were able to adjust for many important risk factors for adverse birth outcomes in a large study population.

\section{METHODS}

\section{Study design}

We conducted a cross sectional analysis of the relation between adverse birth outcomes and TTHMs in Massachusetts drinking water. We used a semi-individual study design, ${ }^{34}$ estimating maternal exposure to DBPs from city specific aggregate monitoring data while utilising individual information on potential confounding variables and the outcomes of interest. Data extracted from birth records and hospital worksheets during $1990(\mathrm{n}=94407)$ were supplied by the

\section{Policy implications}

- There were associations for TTHM levels above $80 \mu \mathrm{g} / \mathrm{l}$, the current maximum contaminant level allowed in the USA.

- While the effect of DBPs on fetal growth retardation may be small in magnitude, this remains an important public health issue due to widespread exposure.

- Further research is needed to evaluate the effects of specific disinfection byproducts, including non-volatile compounds.

Massachusetts Department of Public Health. The study population included singleton infants born to residents of communities that routinely monitored trihalomethanes $(\mathrm{n}=57378)$. We restricted the analyses to infants between 22 and 45 gestational weeks weighing more than $200 \mathrm{~g}$ at birth $(\mathrm{n}=56513)$.

\section{Birth data}

Infant birth weight and gestational age were abstracted from birth records. The recorded gestational age was determined from maternal recall of the date of last menses. Prematurity was defined as less than 37 gestational weeks and low birth weight as less than $2500 \mathrm{~g}$. Infants were considered small for gestational age if they were in the lowest 10th centile of birth weight for each gestational week stratified by infant gender and maternal race (African American versus all other races combined). Gender and race specific deciles were determined from the complete dataset of all births in Massachusetts during 1990. The dichotomous outcomes (low birth weight, small for gestational age, and preterm delivery) were not mutually exclusive. For example, an infant could be classified as both preterm and small for gestational age. Term normal weight infants ( $>37$ gestational weeks and $>2500 \mathrm{~g}$ ) served as the comparison group when calculating exposure odds ratios in the logistic regression models.

\section{Exposure data}

Drinking water is supplied by local water systems in Massachusetts, although multiple towns may share a common source. Utilities that disinfect their water and serve populations greater than 10000 are required to monitor trihalomethane concentrations every quarter. Some towns with historically low trihalomethane levels are only required to monitor DBPs annually. We abstracted trihalomethane data

Table 1 Odds ratios and $95 \% \mathrm{Cl}$ from previous studies of fetal development and trihalomethane (THM) exposure

\begin{tabular}{|c|c|c|c|c|c|}
\hline \multirow[b]{2}{*}{ Study } & \multicolumn{3}{|l|}{ Odds ratio $(95 \% \mathrm{Cl})$} & \multicolumn{2}{|c|}{ THM $(\mu \mathrm{g} / \mathrm{l})$ exposure group } \\
\hline & Low birth weight & SGA & Preterm delivery & Highest level & Reference \\
\hline Dodds et $a^{\beta 0}$ & $1.04(0.92$ to 1.18$)$ & $1.08(0.99 \text { to } 1.18)^{*}$ & 0.97 (0.87 to 1.09 ) & $>100$ & $<50$ \\
\hline Bove et $a^{25-27}$ & $\begin{array}{l}1.3(1.1 \text { to } 1.5) \\
1.42(1.22 \text { to } 1.65) \ddagger\end{array}$ & $\begin{array}{l}1.22(1.07 \text { to } 1.40) \dagger \\
1.50(1.14 \text { to } 1.94) \dagger\end{array}$ & $1.0(0.9$ to 1.1$)$ & $\begin{array}{l}>80 \\
80-100 \\
>100\end{array}$ & $\begin{array}{l}\leqslant 20 \\
\leqslant 20 \\
\leqslant 20\end{array}$ \\
\hline Gallagher et apq & $\begin{array}{l}2.1(1.0 \text { to } 4.8) \S \\
5.9(2.0 \text { to } 17.0) \text { q }\end{array}$ & & $1.0(0.3$ to 2.8$)$ & $\begin{array}{l}>60 \\
>60\end{array}$ & $\begin{array}{l}\leqslant 20 \\
\leqslant 20\end{array}$ \\
\hline Savitz et $a^{R 4}$ & $\begin{array}{l}1.5(1.0 \text { to } 2.3) \\
1.3(0.8 \text { to } 2.1)\end{array}$ & & $\begin{array}{ll}1.2 & (0.8 \text { to } 1.8) \\
0.9 & (0.6 \text { to } 1.5)\end{array}$ & $\begin{array}{l}63.4-82.7 \\
>82.8\end{array}$ & $\begin{array}{l}40.8-63.3 \\
40.8-63.3\end{array}$ \\
\hline Kramer et a ${ }^{8}$ & $\begin{array}{ll}1.3 & (0.8 \text { to } 2.2) \\
1.0 & (0.7 \text { to } 1.5)\end{array}$ & $\begin{array}{ll}1.8 & (1.1 \text { to } 2.9) \dagger \\
1.7 & (0.9 \text { to } 2.9) \dagger\end{array}$ & $\begin{array}{ll}1.1 & (0.7 \text { to } 1.6) \\
1.0 & (0.6 \text { to } 1.5)\end{array}$ & $\begin{array}{l}>10 \mathrm{CHCl}_{3} \\
>10 \mathrm{BDCM}\end{array}$ & $\begin{array}{l}\text { ND } \\
\text { ND }\end{array}$ \\
\hline
\end{tabular}

Abbreviations: $\mathrm{CHCl}_{3}$, chloroform; $\mathrm{ND}$, non-detectable; $\mathrm{BDCM}$, bromodichloromethane.

*SGA defined as lowest $10 \%$ of birth weight for each gestational week.

†SGA defined as lowest $5 \%$ of birth weight for each gestational week.

$\ddagger 50 \% \mathrm{Cl}$.

$\S$ Estimate for elevated third trimester exposure among all births.

IEstimate for elevated third trimester exposure among term births. 
Table 2 Total trihalomethane ( $\mathrm{g} / \mathrm{ll})$ data for 96 Massachusetts communities

\begin{tabular}{lcccc}
\hline Period & 25th centile & Median & 75th centile & 90th centile \\
\hline 1989 & & & & \\
April-June & 9.7 & 25.5 & 40.5 & 59.0 \\
July-September & 11.0 & 34.8 & 53.0 & 81.6 \\
October-December & 9.5 & 27.9 & 51.0 & 64.5 \\
1990 & 9.1 & 25.5 & 47.6 & 61.3 \\
January-March & 13.0 & 26.5 & 51.8 & 64.8 \\
April-June & 14.2 & 32.7 & 55.8 & 83.7 \\
July-September & 11.5 & 28.3 & 50.3 & 67.7 \\
October-December & & &
\end{tabular}

Table 3 Characteristics of singleton infants greater than $200 \mathrm{~g}$ and between 22 and 45 gestational weeks born in Massachusetts in 1990

\begin{tabular}{|c|c|c|c|c|c|}
\hline & Study population & Preterm & SGA* & LBW* & $\begin{array}{l}\text { Mean birth weight } \\
(\mathrm{g})^{*}\end{array}$ \\
\hline Total births & 56513 & 3173 & 5310 & 1325 & 3458 \\
\hline \multicolumn{6}{|l|}{ Maternal race } \\
\hline Caucasian & 42047 (74.4\%) & $5.0 \%$ & $9.2 \%$ & $2.2 \%$ & 3503 \\
\hline African-American & 6025 (10.7\%) & $11.6 \%$ & $9.2 \%$ & $4.9 \%$ & 3310 \\
\hline Other & $5907(10.5 \%)$ & $8.6 \%$ & $13.6 \%$ & $3.2 \%$ & 3359 \\
\hline Asian & $2428(4.3 \%)$ & $9.0 \%$ & $17.3 \%$ & $4.0 \%$ & 3263 \\
\hline American Indian & $106(0.2 \%)$ & $8.9 \%$ & $16.3 \%$ & $5.8 \%$ & 3336 \\
\hline \multicolumn{6}{|l|}{ Maternal age (y) } \\
\hline $11-22$ & 11024 (19.5\%) & $8.7 \%$ & $14.0 \%$ & $3.7 \%$ & 3346 \\
\hline $23-34$ & $38456(68.1 \%)$ & $5.5 \%$ & $9.1 \%$ & $2.4 \%$ & 3482 \\
\hline $35-45$ & 7033 (12.4\%) & $6.4 \%$ & $8.7 \%$ & $2.8 \%$ & 3504 \\
\hline \multicolumn{6}{|l|}{ Maternal education } \\
\hline 9th grade or less & $5192(9.2 \%)$ & $9.8 \%$ & $16.2 \%$ & $4.7 \%$ & 3324 \\
\hline 10th or 11 th grade & $5947(10.5 \%)$ & $10.1 \%$ & $14.7 \%$ & $4.5 \%$ & 3333 \\
\hline High school graduate & $18752(33.2 \%)$ & $6.5 \%$ & $10.6 \%$ & $3.0 \%$ & 3443 \\
\hline At least 1 year of college & $26622(47.1 \%)$ & $4.6 \%$ & $7.4 \%$ & $1.8 \%$ & 3521 \\
\hline \multicolumn{6}{|l|}{ Maternal smoking } \\
\hline 0 cigarettes/day & $44986(79.6 \%)$ & $5.7 \%$ & $8.1 \%$ & $2.0 \%$ & 3502 \\
\hline $1-5$ cigarettes/day & 2404 (4.3\%) & $8.2 \%$ & $13.9 \%$ & $4.8 \%$ & 3338 \\
\hline $6-10$ cigarettes/day & $4409(7.8 \%)$ & $8.4 \%$ & $17.2 \%$ & $5.6 \%$ & 3287 \\
\hline 11 or more cigarettes/day & $4714(8.3 \%)$ & $8.6 \%$ & $19.7 \%$ & $6.1 \%$ & 3259 \\
\hline \multicolumn{6}{|l|}{ Prenatal care (Kessner Index) } \\
\hline No prenatal care & $320(0.6 \%)$ & $31.8 \%$ & $28.0 \%$ & $14.9 \%$ & 3117 \\
\hline Inadequate & $2115(3.7 \%)$ & $13.4 \%$ & $15.6 \%$ & $5.6 \%$ & 3300 \\
\hline Intermediate & $10142(18.0 \%)$ & $9.0 \%$ & $12.8 \%$ & $3.9 \%$ & 3378 \\
\hline Adequate & $43936(77.7 \%)$ & $5.1 \%$ & $9.7 \%$ & $2.2 \%$ & 3485 \\
\hline \multicolumn{6}{|l|}{ Number of previous births } \\
\hline 0 & $25029(44.3 \%)$ & $6.4 \%$ & $11.7 \%$ & $3.1 \%$ & 3414 \\
\hline 1 & $17915(31.7 \%)$ & $5.2 \%$ & $8.2 \%$ & $2.1 \%$ & 3498 \\
\hline 2 or 3 & $11764(20.8 \%)$ & $6.5 \%$ & $8.8 \%$ & $2.5 \%$ & 3493 \\
\hline 4 or more & $1774(3.1 \%)$ & $11.6 \%$ & $11.2 \%$ & $4.1 \%$ & 3454 \\
\hline \multicolumn{6}{|l|}{ Infant gender } \\
\hline Male & $28904(51.2 \%)$ & $5.9 \%$ & $10.0 \%$ & $2.2 \%$ & 3524 \\
\hline Female & $27609(48.9 \%)$ & $6.5 \%$ & $10.0 \%$ & $3.2 \%$ & 3390 \\
\hline \multicolumn{6}{|c|}{ Average TTHM ( $\mu \mathrm{g} / \mathrm{l})$ during pregnancy } \\
\hline 0-60 & $44232(78.3 \%)$ & $6.2 \%$ & $9.7 \%$ & $2.7 \%$ & 3463 \\
\hline$>60-80$ & $7588(13.4 \%)$ & $6.1 \%$ & $10.2 \%$ & $2.5 \%$ & 3458 \\
\hline$>80$ & $4693(8.3 \%)$ & $6.2 \%$ & $12.0 \%$ & $2.9 \%$ & 3416 \\
\hline
\end{tabular}

(1987-93) from the Massachusetts Department of Environmental Protection records for 99 communities. Recorded trihalomethane concentrations were measured using gas chromatography (Environmental Protection Agency (EPA) Method 502.2) and gas chromatography/mass spectrometry (EPA Method 524.2)..$^{35}$ Trihalomethane samples were analysed at the Massachusetts state laboratory (William Wall Experimental Station) until the third quarter of 1990 and at individual Massachusetts or EPA certified laboratories thereafter.

Eighty nine of the 99 towns collected quarterly samples, while the remaining 10 collected annual measurements. Groundwater was the primary water source for the towns with annual monitoring requirements. Groundwater that is not under the influence of surface water has minimal levels of organic matter and typically requires less disinfection than surface water. This results in fewer DBPs and limited seasonal fluctuations in communities which rely on groundwater.

Table 2 presents the quarterly TTHM concentrations in the study population. In communities with multiple sampling sites in the distribution system $(n=64)$, we calculated a quarterly average across locations to assign maternal exposure scores. Three of the original 99 towns were excluded from the study because of considerable missing data. Twenty eight of the remaining 96 communities were missing some quarterly TTHM measurements. We imputed data for the missing values 
Table 4 The frequency of maternal exposure to total trihalomethane (TTHM) concentration during pregnancy

\begin{tabular}{lcccc}
\hline TTHM $(\mu \mathrm{g} / \mathrm{l})$ & First trimester & Second trimester & Third trimester & Pregnancy average \\
\hline $0-60$ & $46366(82 \%)$ & $45746(81 \%)$ & $44556(79 \%)$ & $44232(78 \%)$ \\
$>60-80$ & $5308(9 \%)$ & $5085(9 \%)$ & $5964(11 \%)$ & $7588(13 \%)$ \\
$>80$ & $4339(9 \%)$ & $5682(10 \%)$ & $5721(10 \%)$ & $4693(8 \%)$ \\
\hline
\end{tabular}

based on the city specific quarterly averages from data available from adjacent years (1987-93).

\section{Exposure assessment}

Maternal trihalomethane exposure was estimated from the average TTHM concentration for the town of residence. Maternal residence reported on birth certificates was assumed to be constant for the entire pregnancy. Towns with annual trihalomethane measurements were assumed to have constant levels throughout the year, therefore residents were assigned the annual value for each trimester. Trimester specific and pregnancy average exposures were assigned based on the month of birth. Third trimester TTHM exposure was determined from the current quarterly average if the infant was born in the second or third month of that quarter. If the infant was born in the first month of a quarter, the third trimester exposure was assigned the value from the previous quarter. First and second trimester exposures were determined from the two quarters preceding the third trimester designation. We calculated an average maternal pregnancy exposure from the trimester specific values. Premature infants less than 29 gestational weeks were not assigned a third trimester value, so pregnancy average scores were based on exposures during the first and second trimesters.

\section{Data analysis}

The Massachusetts birth data included individual information on numerous potential confounding variables. The following maternal risk factors were included in the regression models as dichotomous variables: diabetes, eclampsia, hydramnios, chronic hypertension, hypertension during pregnancy, incompetent cervix, lung disease, renal disease, uterine bleeding, previous preterm delivery, and previous birth of an infant weighing greater than $4000 \mathrm{~g}$. We also controlled for gestational age (cubic polynomial) in the birth weight analyses. Adequacy of prenatal care was determined by the Kessner Index, which incorporates gestational age, timing of the first prenatal visit, and total number of prenatal visits. ${ }^{36}$ We included dummy variables for prenatal care (none, inadequate, intermediate, and adequate), maternal race (Caucasian, African American, Asian, Native American, and other) and parity $(0,1,2$ or 3 , and 4 or more children). For maternal education, we included indicators for 9th grade or less, 10th grade, 11 th grade, completion of high school, and completion of at least one year of college. The effect estimates (and standard errors) for 10th and 11 th grade education were similar in the regression analyses, so we combined them to improve precision.

We relied on findings from a previous analysis to determine the best modelling approach for continuous maternal risk factors. ${ }^{37}$ In that analysis, non-parametric smooth functions were used to model the potential non-linear dependence of birth weight on maternal age and smoking. The authors found an inverted $U$ shaped relation of birth weight and maternal age, so we included a quadratic polynomial for maternal age in the regression models. They also found a strong inverse relation between smoking and infant birth weight. That relation became less steep with increasing cigarette use, so we grouped mothers into the following categories: non-smokers, light smokers ( $1-5$ cigarettes per day), moderate smokers (6-10 cigarettes per day), and heavy smokers ( 11 or more cigarettes per day).

Alcohol consumption is another important risk factor for adverse developmental outcomes. ${ }^{38}$ The Massachusetts Department of Public Health had advised that the birth certificate data on maternal alcohol use were considered of poor quality and validity. Preliminary analyses indicated that alcohol was not associated with birth weight, so we did not include maternal alcohol consumption in the analyses. We merged 1990 US census data with the birth data to provide further adjustment of socioeconomic status. We adjusted for median household income by census tract for every county but Barnstable County. The Massachusetts Department of Public Health did not code the birth data by census tract for Barnstable County, so we adjusted for median household income based on mother's zip code of residence.

\section{Statistical methods}

Linear regression was used to evaluate the association between TTHMs and gestational age for all births and the association between TTHMs and birth weight for term births. We used logistic regression to estimate odds ratios and 95\% confidence intervals for the dichotomous outcomes. Pearson correlation coefficients were used to describe the relation between different periods of exposure. All linear and logistic regression analyses were performed using SAS PC statistical software.

\section{RESULTS}

There were 1325 low birth weight, 5310 SGA, and 3173 premature infants in the study population (table 3 ). Fifty one per cent of the infants in the study were male. Seventy four per cent of the mothers were Caucasian and 11\% were African American. Racial differences were evident, with a lower frequency of adverse developmental endpoints occurring among Caucasian infants. The average age of mothers in the study population was 28 years, with $68 \%$ of the pregnancies occurring between 23 and 34 years of age. Younger mothers (aged 11-22) were more likely to give birth to premature, small for gestational age and low birth weight infants. Other determinants of adverse reproductive outcomes controlled for in the analyses included infant gender, parity, adequacy of prenatal care, maternal education, and maternal cigarette use.

Table 4 presents trimester specific and pregnancy average TTHM exposures. On average, $80 \%$ of the study population resided in towns with TTHM concentrations of $60 \mu \mathrm{g} / \mathrm{l}$ or less across the four exposure windows. Eight per cent of women had a pregnancy average TTHM exposure greater than $80 \mu \mathrm{g} / \mathrm{l}$, with slightly higher frequencies for trimester specific exposures. Average TTHM exposure was $39 \mu \mathrm{g} / \mathrm{l}$ during the first and second trimesters and $38 \mu \mathrm{g} / \mathrm{l}$ during the third trimester. These exposure indices were correlated between successive trimesters $(r=0.50$ to 0.66$)$ and between the specific trimesters and the pregnancy average values ( $r=0.81$ to 0.91$)$.

\section{Birth weight}

We observed associations between pregnancy average and trimester specific TTHM exposures and birth weight among term 
Table 5 The effect of trimester specific and pregnancy average total trihalomethane (TTHM) exposure on birth weight among term births

\begin{tabular}{|c|c|c|c|c|}
\hline \multirow[b]{2}{*}{ ТТНM ( $\mu \mathrm{g} / \mathrm{l})$} & \multicolumn{4}{|l|}{$\Delta$ Birth weight $(\mathrm{g})$} \\
\hline & First trimester & Second trimester & Third trimester & Pregnancy average \\
\hline \multicolumn{5}{|l|}{ Crude } \\
\hline $\begin{array}{l}0-60 \\
>60-80 \\
>80\end{array}$ & $\begin{array}{l}\text { Reference } \\
-3 \quad(-18 \text { to } 11) \\
-21 \quad(-36 \text { to }-6)\end{array}$ & $\begin{array}{l}\text { Reference } \\
-7 \quad(-22 \text { to } 8) \\
-29(-43 \text { to }-15)\end{array}$ & $\begin{array}{l}\text { Reference } \\
-3(-17 \text { to } 11) \\
-22(-36 \text { to }-8)\end{array}$ & $\begin{array}{l}\text { Reference } \\
-5(-18 \text { to } 7) \\
-47 \quad(-62 \text { to }-31)\end{array}$ \\
\hline $\begin{array}{l}\text { Per each } 20 \mu g / l \\
\text { p value }\end{array}$ & $\begin{array}{l}-1.6(-3.8 \text { to } 0.5) \\
0.14\end{array}$ & $\begin{array}{l}-2.9(-5.3 \text { to }-0.6) \\
0.01\end{array}$ & $\begin{array}{l}-3.3(-6.0 \text { to }-0.6) \\
0.02\end{array}$ & $\begin{array}{l}-3.4(-6.1 \text { to }-0.6) \\
0.02\end{array}$ \\
\hline \multicolumn{5}{|l|}{ Adjusted* } \\
\hline $\begin{array}{l}0-60 \\
>60-80 \\
>80\end{array}$ & $\begin{array}{l}\text { Reference } \\
-4(-18 \text { to } 9) \\
-17(-31 \text { to }-3)\end{array}$ & $\begin{array}{l}\text { Reference } \\
-5(-19 \text { to } 9) \\
-23(-36 \text { to }-10)\end{array}$ & $\begin{array}{l}\text { Reference } \\
-9 \quad(-22 \text { to } 4) \\
-11 \quad(-24 \text { to } 2)\end{array}$ & $\begin{array}{l}\text { Reference } \\
-1 \quad(-12 \text { to } 11) \\
-32(-47 \text { to }-18)\end{array}$ \\
\hline $\begin{array}{l}\text { Per each } 20 \mu \mathrm{gg} / \mathrm{l} \\
\text { p value }\end{array}$ & $\begin{array}{l}-1.8 \text { (-3.8 to } 0.2) \\
0.08\end{array}$ & $\begin{array}{l}-2.6 \\
0.02\end{array}$ & $\begin{array}{l}-1.8 \text { (-4.4 to } 0.8) \\
0.17\end{array}$ & $\begin{array}{l}-2.8(-5.5 \text { to }-0.2) \\
0.03\end{array}$ \\
\hline
\end{tabular}

*Regression coefficients adjusted for gestational age, infant gender, adequacy of prenatal care, maternal race, maternal education, maternal smoking, maternal age, parity, median household income, previous infant weighing $4000 \mathrm{~g}$ or more, previous preterm delivery, and maternal medical history (diabetes, eclampsia, hydramnios, chronic hypertension, hypertension during pregnancy, incompetent cervix, lung disease, renal disease, and uterine bleeding).

Table 6 Crude and adjusted odds ratios and $95 \% \mathrm{Cl}$ of low birth weight for trimester specific and pregnancy average total trihalomethane (TTHM) exposure among term births

\begin{tabular}{|c|c|c|c|c|}
\hline \multirow[b]{2}{*}{ TTHM ( $(\mu \mathrm{g} / \mathrm{l})$} & \multicolumn{4}{|l|}{ Low birth weight } \\
\hline & First trimester & Second trimester & Third trimester & Pregnancy average \\
\hline \multicolumn{5}{|c|}{ Crude OR $(95 \% \mathrm{Cl})$} \\
\hline $0-60$ & 1.0 & 1.0 & 1.0 & 1.0 \\
\hline$>60-80$ & $1.06(0.89$ to 1.28$)$ & 0.87 (0.71 to 1.07$)$ & 0.97 (0.81 to 1.16$)$ & 0.91 (0.77 to 1.08 ) \\
\hline$>80$ & $0.93(0.75$ to 1.13 ) & 1.09 (0.92 to 1.30 ) & 1.11 (0.93 to 1.32$)$ & 1.08 (0.89 to 1.31$)$ \\
\hline \multicolumn{5}{|c|}{ Adjusted OR $(95 \% \mathrm{Cl})$ * } \\
\hline $0-60$ & 1.0 & 1.0 & 1.0 & 1.0 \\
\hline$>60-80$ & 1.13 (0.93 to 1.38 ) & 0.93 (0.75 to 1.15 ) & 1.08 (0.90 to 1.31 ) & 0.97 (0.81 to 1.26$)$ \\
\hline$>80$ & 0.98 (0.79 to 1.21 ) & 1.14 (0.95 to 1.38 ) & 1.09 (0.91 to 1.31 ) & 1.05 (0.85 to 1.29 ) \\
\hline
\end{tabular}

*Odds ratios adjusted for gestational age, infant gender, adequacy of prenatal care, maternal race, maternal education, maternal smoking, maternal age, parity, median household income, previous infant weighing $4000 \mathrm{~g}$ or more, previous preterm delivery, and maternal medical history (diabetes, eclampsia, hydramnios, chronic hypertension, hypertension during pregnancy, incompetent cervix, lung disease, renal disease, and uterine bleeding).

Table 7 Crude and adjusted relative risks of small for gestational age for trimester specific and pregnancy average total trihalomethane (TTHM) exposure among term births

\begin{tabular}{|c|c|c|c|c|}
\hline \multirow[b]{2}{*}{ TTHM ( $\mu \mathrm{g} / \mathrm{I})$} & \multicolumn{4}{|c|}{ Small for gestational age } \\
\hline & First trimester & Second trimester & Third trimester & Pregnancy average \\
\hline \multicolumn{5}{|c|}{ Crude OR $(95 \% \mathrm{Cl})$} \\
\hline $0-60$ & 1.0 & 1.0 & 1.0 & 1.0 \\
\hline$>60-80$ & $1.06(0.97$ to 1.17$)$ & 1.05 (0.95 to 1.16$)$ & 1.03 (0.94 to 1.13 ) & $1.06(0.98$ to 1.15$)$ \\
\hline$>80$ & $1.11(1.09$ to 1.23$)$ & $1.20(1.10$ to 1.31$)$ & 1.09 (1.05 to 1.26 ) & $1.27(1.15$ to 1.40$)$ \\
\hline \multicolumn{5}{|c|}{ Adjusted OR $(95 \% \mathrm{Cl})$ * } \\
\hline $0-60$ & 1.0 & 1.0 & 1.0 & 1.0 \\
\hline$>60-80$ & $1.00(0.89$ to 1.10$)$ & 0.99 (0.89 to 1.10$)$ & 0.98 (0.89 to 1.09 ) & 1.00 (0.92 to 1.09$)$ \\
\hline$>80$ & $1.09(0.98$ to 1.21$)$ & $1.13(1.03$ to 1.24$)$ & 1.03 (0.94 to 1.14 ) & $1.14(1.02$ to 1.26$)$ \\
\hline
\end{tabular}

*Odds ratios adjusted for adequacy of prenatal care, maternal education, maternal smoking, maternal age, parity, median household income, previous infant weighing $4000 \mathrm{~g}$ or more, previous preterm delivery, and maternal medical history (diabetes, eclampsia, hydramnios, chronic hypertension, hypertension during pregnancy, incompetent cervix, lung disease, renal disease, and uterine bleeding).

births (table 5). After adjusting for gestational age and other covariates, a $2.8 \mathrm{~g}(95 \% \mathrm{CI}-5.5$ to -0.2$)$ decrease in birth weight was observed for every $20 \mu \mathrm{g} / \mathrm{l}$ increase in pregnancy average TTHM exposure. A similar effect was observed for second trimester TTHM exposure $(-2.6 \mathrm{~g} ; 95 \% \mathrm{CI}-4.8$ to -0.4 per $20 \mu \mathrm{g} / \mathrm{l})$. Compared to the reference group ( $\leqslant 60 \mu \mathrm{g} / \mathrm{l}$ TTHM), we found a $32 \mathrm{~g}(95 \% \mathrm{CI}-47$ to -18$)$ reduction in birth weight among infants whose mothers had pregnancy average exposures greater than $80 \mu \mathrm{g} / \mathrm{l}$. Mothers in the highest exposure group during the second trimester had infants that weighed $23 \mathrm{~g}(95 \% \mathrm{CI}-36$ to -10$)$ less than the comparison group.

\section{Low birth weight}

No consistent associations were detected for TTHM exposure and low birth weight among term births (table 6). Increased risks were detected for intermediate first trimester (OR 1.13; 95\% CI 0.93 to 1.38 ) and high second trimester exposures (OR 
Table 8 The effect of trimester specific and pregnancy average total trihalomethane (TTHM) exposure on gestational age among all births

\begin{tabular}{|c|c|c|c|c|}
\hline \multirow[b]{2}{*}{ TTHM ( $\mu \mathrm{g} / \mathrm{l})$} & \multicolumn{4}{|c|}{$\Delta$ Gestational age (weeks) } \\
\hline & First trimester & Second trimester & Third trimester & Pregnancy average \\
\hline \multicolumn{5}{|l|}{ Crude } \\
\hline $0-60$ & Reference & Reference & Reference & Reference \\
\hline$>60-80$ & $0.05(-0.01$ to 0.11$)$ & $0.06(0.00$ to 0.13$)$ & $0.05(0.00$ to 0.10$)$ & $0.07(0.02$ to 0.12$)$ \\
\hline$>80$ & $0.00 \quad(-0.07$ to 0.06$)$ & $0.08(0.02$ to 0.14$)$ & $0.07(0.02$ to 0.13$)$ & $0.07(0.03$ to 0.11$)$ \\
\hline Per each 20 pg/l & $0.02(0.01$ to 0.03$)$ & 0.03 (0.02 to 0.04$)$ & 0.02 (0.01 to 0.03$)$ & 0.02 (0.01 to 0.02$)$ \\
\hline$p$ value & 0.001 & $<0.0001$ & $<0.0001$ & 0.003 \\
\hline \multicolumn{5}{|l|}{ Adjusted* } \\
\hline $0-60$ & Reference & Reference & Reference & Reference \\
\hline$>60-80$ & 0.02 (-0.04 to 0.09$)$ & $0.06(0.00$ to 0.13$)$ & $0.04(-0.02$ to 0.09$)$ & $0.04(-0.01$ to 0.09$)$ \\
\hline$>80$ & $-0.02(-0.09$ to 0.04$)$ & $0.09(0.02$ to 0.15$)$ & $0.05(0.00$ to 0.11$)$ & $0.08(0.01$ to 0.14$)$ \\
\hline Per each $20 \mu g / l$ & $0.01 \quad(0.00$ to 0.02$)$ & $0.02(0.01$ to 0.03$)$ & $0.01(0.00$ to 0.02$)$ & $0.02(0.01$ to 0.03$)$ \\
\hline$p$ value & 0.07 & $<0.0001$ & 0.008 & 0.003 \\
\hline
\end{tabular}

* Regression coefficients adjusted for infant gender, adequacy of prenatal care, maternal race, maternal education, maternal smoking, maternal age, parity, median household income, previous infant weighing $4000 \mathrm{~g}$ or more, previous preterm delivery, and maternal medical history (diabetes, eclampsia, hydramnios, chronic hypertension, hypertension during pregnancy, incompetent cervix, lung disease, renal disease, and uterine bleeding).

Table 9 Crude and adjusted odds ratios and $95 \% \mathrm{Cl}$ of preterm delivery for trimester specific and pregnancy average total trihalomethane (TTHM) exposure among all births

\begin{tabular}{|c|c|c|c|c|}
\hline \multirow[b]{2}{*}{ TTHM ( $\mu \mathrm{g} / \mathrm{l})$} & \multicolumn{4}{|l|}{ Preterm delivery } \\
\hline & First trimester & Second trimester & Third trimester & Pregnancy average \\
\hline \multicolumn{5}{|c|}{ Crude OR $(95 \% \mathrm{CI})$} \\
\hline $0-60$ & 1.0 & 1.0 & 1.0 & 1.0 \\
\hline$>60-80$ & $0.97(0.86$ to 1.10$)$ & $1.03(0.91$ to 1.17$)$ & $1.00(0.88$ to 1.13$)$ & 0.90 (0.80 to 1.01$)$ \\
\hline$>80$ & $1.00(0.88$ to 1.13$)$ & $0.92(0.81$ to 1.04$)$ & $1.01(0.89$ to 1.14$)$ & 0.93 (0.85 to 1.01 ) \\
\hline \multicolumn{5}{|c|}{ Adjusted OR $(95 \% \mathrm{CI})$ * } \\
\hline $0-60$ & 1.0 & 1.0 & 1.0 & 1.0 \\
\hline$>60-80$ & $0.96(0.84$ to 1.10$)$ & $1.02(0.89$ to 1.16$)$ & 0.99 (0.87 to 1.13$)$ & $1.00(0.89$ to 1.12$)$ \\
\hline$>80$ & $1.01(0.88$ to 1.16$)$ & $0.90(0.79$ to 1.03$)$ & 0.97 (0.85 to 1.11$)$ & 0.90 (0.77 to 1.04$)$ \\
\hline
\end{tabular}

*Odds ratios adjusted for infant gender, adequacy of prenatal care, maternal race, maternal education, maternal smoking, maternal age, parity, median household income, previous infant weighing $4000 \mathrm{~g}$ or more, previous preterm delivery, and maternal medical history (diabetes, eclampsia, hydramnios, chronic hypertension, hypertension during pregnancy, incompetent cervix, lung disease, renal disease, and uterine bleeding).

1.14; $95 \%$ CI 0.95 to 1.38 ). Similar effects were observed for intermediate and high third trimester TTHM exposures.

\section{Small for gestational age}

We found a higher frequency of SGA births among mothers with pregnancy average TTHM exposures greater than $80 \mu \mathrm{g} / \mathrm{l}$ (OR 1.14; 95\% CI 1.02 to 1.26) compared to the reference group (table 7). Increased risk of SGA was also detected for first (OR $1.09 ; 95 \%$ CI 0.98 to 1.21 ) and second (OR 1.13; $95 \%$ CI 1.03 to 1.24) trimester TTHM exposures.

\section{Gestational duration}

We observed small increases in gestational age per $20 \mu \mathrm{g} / \mathrm{l}$ TTHM during the entire pregnancy and for each trimester (table 8). Statistically significant associations were detected for mothers in the highest TTHM exposure group ( $>80 \mu \mathrm{g} / \mathrm{l}$ ) during the second trimester (0.09 gestational weeks; $95 \%$ CI 0.02 to 0.15$)$ and over the entire pregnancy (0.08 gestational weeks; $95 \%$ CI 0.01 to 0.14 ). There was little evidence of an association between TTHM exposure and preterm delivery. In fact, the data indicate that mothers with higher exposures during the second trimester (OR 0.90; 95\% CI 0.79 to 1.03 ) and the entire pregnancy (OR $0.90 ; 95 \%$ CI 0.77 to 1.04 ) were less likely to deliver prematurely (table 9).

\section{DISCUSSION}

Our findings indicate that exposure to high trihalomethane levels during pregnancy is associated with reductions in birth weight among term births. After adjusting for gestational age and other covariates, we observed reductions of $2.8 \mathrm{~g}$ for each 20 $\mu \mathrm{g} / \mathrm{l}$ increase in pregnancy average TTHM concentration and 2.6 $\mathrm{g}$ for each $20 \mu \mathrm{g} / \mathrm{l}$ increase in second trimester TTHM concentration (table 5). Maternal exposure to increased TTHMs $(>80 \mu \mathrm{g} / \mathrm{l})$ was associated with lower birth weight when compared to the reference group $(\leqslant 60 \mu \mathrm{g} / \mathrm{l})$. The largest effects were observed for pregnancy average $(-32 \mathrm{~g} ; 95 \%$ CI -47 to -18$)$ and second trimester $(-23 \mathrm{~g} ; 95 \% \mathrm{CI}-36$ to -10$)$ exposures. Bove $^{27}$ was the only investigator to examine the effect of TTHM on birth weight as a continuous measure, reporting a $70 \mathrm{~g}(95 \%$ CI -106 to -35$)$ decrease in birth weight for each $100 \mu \mathrm{g} / \mathrm{l}$ increase in TTHM. This is considerably larger than the pregnancy average estimate from this study, which would have predicted a $14 \mathrm{~g}$ decrease if extrapolated to $100 \mu \mathrm{g} / \mathrm{l}$. However, birth weight deficits were only found in the highest exposure category, suggesting a non-linear response in our data.

Overall, we found weaker associations between TTHMs and adverse developmental outcomes than previously reported. Our data indicate that exposure to TTHMs may shift the birth weight distribution downward among term births without significantly impacting the prevalence of low birth weight infancy. We found a small increased risk for term low birth weight among mothers with increased second trimester TTHM exposures (OR 1.14; 95\% CI 0.95 to 1.38). In contrast to findings from Gallagher and colleagues, ${ }^{29}$ we found a similar effect of TTHM on low birth weight among all births (data not presented). 
Since low birth weight is a function of fetal growth rate and gestational duration, we evaluated the impact of TTHM on both small for gestational age and premature infants. We observed an increased risk of SGA among mothers with high second trimester (OR 1.13; 95\% CI 1.03 to 1.24 ) and pregnancy average (OR 1.14; 95\% CI 1.02 to 1.26) TTHM exposures. These relative risks are similar in magnitude to the study by Dodds and colleagues, ${ }^{30}$ but are substantially smaller than reports by Kramer and colleagues ${ }^{28}$ and Bove..$^{27}$ Consistent with other studies, we did not detect an association between TTHM exposure and preterm delivery. Therefore, DBPs do not appear to adversely impact length of gestation. In fact, our data indicate that TTHMs are associated with small increases in gestational duration. The clinical significance of such a small increase in gestational duration is unclear, especially given the poor precision of gestational age estimates. ${ }^{39}$

The third trimester is considered the most critical period of exposure for a developing fetus. While fetal growth tends to peak between 43 and 44 weeks, second trimester exposures may be important as well. Ninety five per cent of fetal growth occurs after the 20 th gestational week ${ }^{40}$ with increases in fetal growth rate beginning after 34 gestational weeks. ${ }^{41}$ Compared to the third trimester, we saw slightly stronger effects of second trimester TTHM exposure on fetal growth indices. Our estimates of maternal exposure between successive trimesters are highly correlated ( $r=0.50$ to 0.65 ), so we may not be able to differentiate the effect of DBPs between the different trimesters.

One of the strengths of our study was the comprehensive information on individual pregnancy risk factors available from birth records and hospital worksheets. The large study population allowed us to control for important maternal risk factors not considered in previous studies. Confounding by gestational age and other maternal risk factors had the largest impact on the association of TTHMs and birth weight (tables 5-9) but did not have much of an effect on the relation between TTHMs and the other outcomes. Nevertheless, the potential for residual confounding remains, since we were not able to control for other reproductive risk factors (marital status, weight gain during pregnancy, maternal nutrition, alcohol use, etc). These risk factors would have to be associated with TTHMs as well as the reproductive outcomes to be confounders.

A potential limitation of our study is exposure misclassification, since we relied on the address of residence at time of birth to assign exposure status. Previous reports indicate that a considerable number of women move during pregnancy $(10-37 \%) .{ }^{28}$ An additional limitation of our study is the inability to distinguish the impact of specific routes of exposure (ingestion, inhalation, and dermal absorption) to volatile compounds such as the trihalomethanes. ${ }^{42}$ Although the findings are inconsistent, a few studies have been able to evaluate the impact of water consumption ${ }^{24}{ }^{43}$ and showering. ${ }^{43}$ While these sources of exposures are important, any resulting misclassification errors in our study are likely to be independent of the outcome measures. Non-differential exposure misclassification typically biases effect estimates towards the null, which may explain the smaller relative risks in this study compared to previous reports. Despite the potential for non-differential misclassification, the aggregate measures of exposure should reflect the gross temporal and spatial differences in the exposure experience of our study population.

Variability in DBP formation has been noted in distribution systems given adequate chlorine residual. Trihalomethanes can increase further out in the distribution system, with more variation observed in the brominated compounds (compared to chloroform). ${ }^{44}$ In contrast, haloacetic acids may undergo biological degradation since maximum values have been found at the closest sampling locations ${ }^{45}$ Understanding these relations is important for exposure assessment strategies that rely on limited DBP monitoring data. While we were able to capture some of the temporal variability associated with DBP formation through the use of routinely monitored exposure data, our inability to account for spatial variability may also result in misclassification. Gallagher and colleagues ${ }^{29}$ were able to address seasonal and spatial variation in trihalomethane concentrations by using specific sampling dates and incorporating hydraulic characteristics in a computer simulation model of residential exposures. They reported the largest relative risk for low birth weight (OR 2.1; 95\% CI 1.0 to 4.8 ) and term low birth weight (OR 5.9; 95\% CI 2.0 to 17.0) despite low TTHM concentrations.

Only one study has explored the role of other DBPs on adverse reproductive outcomes. Klotz and colleagues ${ }^{46}$ reported an OR of 1.2 (95\% CI 0.5 to 2.6) for total haloacetic acids $>35 \mu \mathrm{g} / \mathrm{l}$ compared to $<3 \mu \mathrm{g} / \mathrm{l}$ and an OR of 1.3 (95\% CI 0.6 to 2.5 ) for haloacetonitriles $>3.0 \mu \mathrm{g} / \mathrm{l}$ compared to $<0.5$ $\mu \mathrm{g} / \mathrm{l}$. Kramer and colleagues ${ }^{28}$ reported an $80 \%$ (OR 1.8; 95\% CI 0.9 to 3.4 ) increased risk of SGA for exposure to total organic halides $>100 \mu \mathrm{g} / \mathrm{l}$. Total organic halides were highly correlated with trihalomethane concentrations, so the authors were not able to determine the independent effect of each DBP marker. More research is needed to identify the specific compounds that DBP surrogates represent. If TTHM concentration (or another surrogate marker) is a poor proxy for specific DBPs, even the most elaborate exposure modelling will not be able to fully elucidate the potentially harmful effects of DBPs on fetal development. Our results add to the body of literature indicating that there are such effects, but further research is needed to better delineate them.

\section{ACKNOWLEDGEMENTS}

JM Wright was supported by NIEHS training grant 5 T32 ES07069. We appreciate the guidance of the Massachusetts Department of Public Health and the local water departments. Special thanks to Jim Dillon, Damon Guterman, and Paula Caron of the Massachusetts Department of Environmental Protection.

\section{Authors' affiliations}

J M Wright, J Schwartz, D W Dockery, Environmental Epidemiology Program, Department of Environmental Health, Harvard School of Public Health, Boston, Massachusetts, USA

\section{REFERENCES}

1 National Cancer Institute. Report on the carcinogenesis bioassay of chloroform. NTIS PB-264-018. Bethesda, MD: National Cancer Institute, 1976.

2 National Toxicology Program. Toxicology and carcinogenesis of bromodichloromethane in F344/N rats and B6C3F1 mice. Technica Report Series No. 321. NIH Publication No. 88-2537, CAS No. 75-27-4. Washington, DC:US Department of Public Health and Human Services, 1986.

3 National Toxicology Program. Toxicology and carcinogenesis of tribromomethane (bromoform) in F344/N rats and B6C3F 1 mice. Technical Report Series No. 350. NIH Publication No. 89-2805, CAS No. 75-25-2. Washington, DC: US Department of Public Health and Human Services, 1989.

4 Bull RJ, Sanchez IM, Nelson MA, et al. Liver tumor induction in B6C3F, mice by dichloroacetate and trichloroacetate. Toxicology 1990;63:341-59.

5 Bull RJ, Meier JR, Robinson M, et al. Evaluation of mutagenic and carcinogenic properties of brominated and chlorinated acetonitriles: by-products of chlorination. Fund App Toxicol 1985;5:1065-74.

6 Kurokawa Y, Aoki S, Matsushima Y, et al. Dose-response studies on the carcinogenicity of potassium bromate in F344 rats after long-term oral administration. J Natl Cancer Inst 1986;77:977-82.

7 Komulainen H, Kosma V-M, Vaittinen S-L, et al. Carcinogenicity of the drinking water mutagen

3-chloro-4-(dichloromethyl)-5-hydroxy-2(5H)-furanone in the rat. J Natl Cancer Inst 1997;89:848-56

8 Cantor KP, Lynch CF, Hildesheim ME, et al. Drinking water source and chlorination byproducts. I. Risk of bladder cancer. Epidemiology 1998;9:21-8.

9 Hildesheim ME, Cantor KP, Lynch CF, et al. Drinking water source and chlorination byproducts. II. Risk of colon and rectal cancers. Epidemiology 1998;9:29-35.

10 McGeehin MA, Reif JS, Becher JC, et al. Case-control study of bladder cancer and water disinfection methods in Colorado. Am J Epidemiol 1993;138:492-501. 
11 King WD Marrett LD. Case-control study of bladder cancer and chlorination by-products in treated water (Ontario, Canada). Cance Causes Control 1996; 7:596-604

12 Koivusalo MT, Hakulinen T, Vartiainen T, et al. Drinking water mutagenicity and urinary tract cancers: a population-based case-control study in Finland. Am J Epidemiol 1998;148:704-12.

13 Koivusalo MT, Pukkala E, Vartiainen T, et al. Drinking water chlorination and cancer-a historical cohort study in Finland. Cancer Causes Control 1997; 8: 192-200.

14 Koivusalo MT, Vartiainen T, Hakulinen T, et al. Drinking water mutagenicity and leukemia, lymphomas and cancers of the liver, pancreas, and soft tissue. Arch Environ Health 1995;50:269-76.

15 Koivusalo MT, Jaakkola JJK, Vartiainen T, et al. Drinking water mutagenicity and gastrointestinal and urinary tract cancers: an ecological study in Finland. Am J Public Health 1994;84:1223-8.

16 Morris RD, Audet AM, Angelillo IF, et al. Chlorination, chlorination by-products, and cancer: a meta-analysis. Am J Public Health 1992;82:955-63.

17 Nieuwenhuijsen MJ, Toledano MR, Eaton NE, et al. Chlorination disinfection by-products in water and their association with adverse reproductive outcomes: a review. Occup Environ Med 2000;57:73-85.

18 Graves CG, Matanoski GM, Tardiff RG. Weight of evidence for an association between adverse reproductive and developmental effects and exposure to disinfection by products: a critical review. Regul Toxicol Pharmacol 2001;34:103-24.

19 Schwetz BA, Leong BKJ, Gehring PJ. Embryo- and fetotoxicity of inhaled chloroform in rats. Toxicol Appl Pharmacol 1974;28:442-51.

20 Murray FJ, Schwetz BA, McBride JG, et al. Toxicity of inhaled chloroform in pregnant mice and their offspring. Toxicol Appl Pharmacol 1979;50:515-22.

21 Ruddick JA, Villeneuve DC, Chu I. A teratological assessment of four trihalomethanes in the rat. J Environ Sci Health B 1983;18:333-49.

22 Thompson DJ, Warner SD, Robinson VB. Teratology studies on orally administered chloroform in the rat and the rabbit. Toxicol Appl Pharmacol 1974:29:348-57.

23 Dowty BJ, Laseter JL. The transplacental migration and accumulation in blood of volatile organic constituents. Pediatr Res 1976;10:696-701.

24 Savitz D, Andrews K, Pastore L. Drinking water and pregnancy outcomes in central North Carolina: source, amount, and trihalomethane levels. Environ Health Perspect 1995; 103:592-6.

25 Bove FJ, Fulcomer MC, Klotz JB, et al. Report on phase IV-A: public drinking water contamination and birth weight, fetal deaths and birth defects, a cross-sectional study. Trenton, NJ: New Jersey Department of Public Health, 1992.

26 Bove FJ, Fulcomer MC, Klotz JB, et al. Public drinking water contamination and outcomes. Am J Epidemiol 1995;141:850-62.

27 Bove FJ. Public drinking water contamination and birth weight, prematurity, fetal deaths, and birth defects. Toxicol Ind Health $1996 ; 12: 255-66$.
28 Kramer $M$, Lynch $C$, Isacson $P$, et al. The association of waterborne chloroform with intrauterine growth retardation. Epidemiology 1992;3:407-13

29 Gallagher MD, Nuckols JR, Stallones L, et al. Exposure to trihalomethanes and adverse pregnancy outcomes. Epidemiology 1998:9:484-9.

30 Dodds L, King W, Woolcott C, et al. Trihalomethanes in public water supplies and adverse birth outcomes. Epidemiology 1999;10:233-7.

31 Tuthill RW, Giusti RA, Moore GS, et al. Health effects among newborns after prenatal exposure to $\mathrm{ClO}_{2}$-disinfected drinking water. Environ Health Perspect 1982:46:39-45.

32 Aschengrau A, Zierler S, Cohen A. Quality of community drinking water and the occurrence of spontaneous abortion. Arch Environ Health 1989;44:283-90.

33 Aschengrau A, Zierler S, Cohen A. Quality of community drinking water and the occurrence of late adverse pregnancy outcomes. Arch Environ Health 1993:48:105-13.

34 Kunzli N, Tager IB. The semi-individual study in air pollution epidemiology: a valid design as compared to ecologic studies. Environ Health Perspect 1997; 105:1078-83.

35 Environmental Protection Agency. Methods for the determination of organic compounds in drinking water. EPA/600/R-95-131-Supplement III. Washington, DC: US Environmental Protection Agency, 1995.

36 Alexander GR, Kotelchuck M. Quantifying the adequacy of prenatal care: a comparison of indices. Public Health Rep 1996;1 11:408-18.

37 Hattis, D, Ryan L, Schwartz J, et al. Technical advisors' 2nd year (1998-99) report to the community assistance panel Massachusetts Military Reservation. Appendix II-Analysis of birth weights, 1999.

38 Kramer MS. Determinants of low birth weight: methodological assessment and meta-analysis. Bull World Health Organ 1987:65:663-737

39 David RJ. The quality and completeness of birthweight and gestational age data in computerized birth files. Am J Public Health 1980;70:964-72.

40 Vorherr H. Factors influencing fetal growth. Am J Obstet Gynecol 1982;142:577-88.

41 Matheus M, Sala MA. A mathematical model for the curves of intrauterine growth. Acta Physiol Lat Am 1980;30:97-9.

42 Weisel CP, Wan-Kuen J. Ingestion, inhalation and dermal exposures to chloroform and trichloroethane from tap water. Environ Health Perspect 1995; 104:48-51.

43 Waller K, Swan SH, DeLorenze G, et al. Trihalomethanes in drinking water and spontaneous abortion. Epidemiology 1998;9:134-40.

44 Brett RW, Calverley RA. A one-year survey of trihalomethane concentration changes within a distribution system. J Am Water Works Assoc 1979:71:515-20.

45 Chen WJ, Weisel CP. Halogenated DBP concentrations in a distribution system. J Am Water Works Assoc 1998;90:151-63.

46 Klotz JB, Pyrch LA. Neural tube defects and drinking water disinfection by-products. Epidemiology 1999;10:383-90. 